\title{
A Mobile Design Environment for Building Form Generation
}

\author{
Mehmet Emin Bayraktar [D \\ Istanbul Technical University, Department of Informatics, Architectural Design Computing Program, Istanbul, Turkey \\ (Corresponding author) \\ Gulen Cagdas \\ Istanbul Technical University, Faculty of Architecture, Department of Architecture, Istanbul, Turkey
}

Received: November 16th 2020, Revised: November 29th 2020, Accepted: December 1st 2020

Refer: Bayraktar, M. E., Cagdas, G., (2020), A Mobile Design Environment for Building Form Generation, Journal of Design Studio, V.2, N.2, pp 131-142,

M. E. Bayraktar ORCID: 0000-0003-4441-7425, G. Cagdas ORCID: 0000-0001-8853-4207, DOI: $10.46474 /$ jds.826659 https://doi.org/10.46474/jds.826659

\begin{abstract}
Computer technology has affected architectural studies as well as other professions. Architectural tools are used in every stage of the design and their primary goals are transferring and sharing the ideas of the architects' mind. Nevertheless, in the early design phase, digital design tools remain ineffective in terms of idea development. Current design software and modeling tools are insufficient for the architect to quickly share ideas and generate alternative suggestions for fast sketching and modeling.

In this paper, a mobile design application is developed. It aims to support open-ended design thinking and to be fast and effective in terms of improving ideas. It is based on augmented reality and it works on mobile phones. In order to evaluate the application, a set of images consisting of tall buildings are shown to users. Then they are asked to model a similar form of their own. At the end, results are assessed with a questionnaire. Using the obtained data, the effectiveness of the digital mobile tool in the early design stage is discussed.
\end{abstract}

Keywords: Digital architectural design tools, Early Design, Augmented reality, Mobile environment, Tall buildings.

\section{Introduction}

Various tools are used in the architectural design process. The main purpose of architectural design tools is to prepare an environment for developing architects' idea, transferring to other media, and communicating with stakeholders through drawings and visual models. The effects of technological changes in the field of computer aided architectural design are observed strongly. In the past, producing, modifying, sharing, and displaying models were the main intention of using the tools. Today, issues such as designing in digital environment, multi-user interaction and online collaboration, augmented reality, generative systems, and the use of artificial intelligence affect the design process. Computer aided approaches are advancing in a parallel manner with the software and hardware improvements. It is unthinkable that this transformation will not influence the design habits of architects.

These are the research questions prepared in this context;

1- How effective are the existing digital media used in the development and representation of initial ideas in the preliminary design phase when making sketch, diagrams and working models?

2- How can productivity be supported in the 
early design by utilizing digital environment?

3- Can mobile digital environment help rapid generation of design alternatives and does that influence productivity?

4- Can alternatives be developed by establishing a relationship between mobile, digital, and physical work environments? Can they transform into prototypes quickly? 5- How does augmented reality support the design environment?

The motivation of this research comes with a suggestion to a problem. In the early stages of design with the help of information technologies, the architect can benefit from alternative mass creation on a mobile device, without depending on computer hardware. From this point on, an augmented reality based mobile application for idea creation environment has been developed and tested with users. The content of the study is limited with high-rise building design topic since form creation problem is encountered predominantly in this type of projects.

There should be no restrictions with the use of tools while developing ideas, especially at the early design stage. Since tools have influence on shaping ideas, it may not be possible to reach satisfying solutions due to the architect's inexperience with the tool or because of the limitations of the tool itself. In order to remove these constraints, an application is created to increase productivity in the form creating activities. If this new environment is used at a stage where thoughts are mostly uncertain and not well defined, it can contribute to diversify and ultimately refine design solutions by generating quicker alternatives to choose among them. The objectives of the research using the potential of augmented reality can be summarized as follows:

1- Providing the opportunity to test mass alternatives with surrounding structures and topography on the project site using the potential of augmented reality, 2- Developing a mobile digital environment similar to modeling experience as if the user works on a physical model, 3- Transferring the final product physically or virtually to other media.

The research consists of three stages, the literature review for the application, the development of the mobile media application, and the evaluation and interpretation of user tests.

\section{Digital environment in architectural design}

Since the 1950s, with the digitization and processing of information, research on digital design has been increasing. Sketchpad application, which is considered as a cornerstone in the field of computer aided design, is an important study because it defines a 3D virtual geometry with vectors, presents a real time manipulation of models and reflects changes that made within a block to the whole drawing which we still use today as primary concepts in our computer aided design tools (Sutherland, 1964). However, the most important claim of Sketchpad program is to demonstrate that a communication environment based on ideas can be established in computer environment with its input and output. Since this study, CAD software has been developing continuously and now they are used by the architects, especially with the widespread use of personal computers. In addition, there are improvements shaping design and production in architecture and construction, such as building information modeling (BIM) systems. Many breakthroughs such as parametric design, decision support mechanisms, generative systems, artificial intelligence support, pedestrian simulations and research like these have paved the way for new thinking methods in the field of architecture (Koutamanis, 2003; Bayazit, 2004). Considering all these advances, it can be said that; computer technology has caused a paradigm shift in architectural design thinking. Today, it is possible to continue this progress even further with innovative approaches.

The aim of design thinking, which is the subject of these achievements in the field of 
architectural design is basically the same. According to Akin (1978), the cognitive part of the design has inputs and outputs and a common mechanism is established by using the notes, models, sketches and similar supporting elements with the other available information of the designer. Also the tools used in early design, such as sketches, are not just output of ideas, but they provide the opportunity to transform ideas and create new ones (Goldschmidt, 1991; Twersky, 1997; Smith, 2012). According to Ackerman (2002) drawings emerged as a communication tool and they are created according to their purpose. In addition, all the tools we use directly has an impact on the design approach and event on the final product itself (Füssler, 2008).

\subsection{Augmented Reality in Design}

Augmented reality (AR) is a mixed environment created by projecting virtual objects or information onto real world video stream. Digital additions are synchronized with the help of a computer and the user perceives these two environments at the same time. Thus, the potential of the virtual world can be used without getting away from the physical environment. The AR experience can be enriched not only by using image but also by additions such as sound, smell, and touch. According to Milgram et al. (1995) augmented reality is a subgroup of mixed reality. They define mixed reality with a reality - virtuality line as in Figure 1. The amount of reality decreases as you go to virtuality from real environment and decreases the other way around.

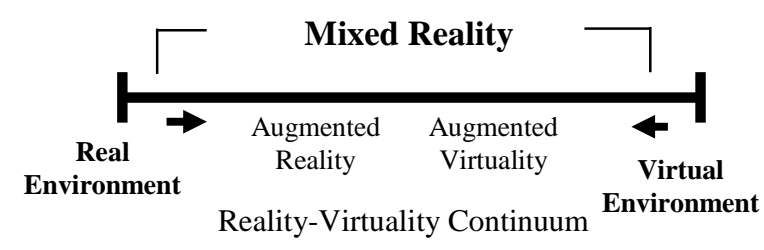

Figure 1. Mixed reality use on the reality-virtuality line (Milgram et al, 1995).
In the past, pioneer works of augmented reality needed to use special, expensive equipment such as custom headsets (Caudell \& Mizell, 1992; Azuma et al; 2001). Due to these limitations, AR technology did not reach to everyone. Nowadays, with the help of mobile devices and tablets more people can have the access to AR systems. Thus, the application areas have expanded and different usage scenarios have emerged (Dimitris, 2017). In the same manner, interest in the field of AR in education has increased substantially compared to previous years (Chen et al, 2017). In architectural design, it is possible to come across studies made for different problems of different scales (Kerr \& Lawson, 2020; Birt et al, 2017; Arashpour, \& Aranda-Mena, 2017).

Another important subject is whether the information placed on the real environment is interactive or not. In the past, displaying information in a virtual setting was the main purpose, but today the approach of manipulating digital content and creating new objects has opened new doors for AR. It makes a difference to work on content in the virtual space than only displaying it. (Figure 2,3).

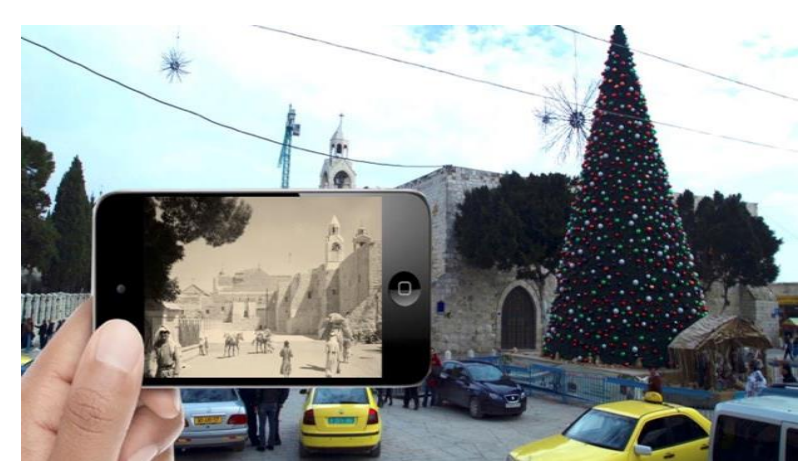

Figure 2: Present day streets and buildings are shown with their history in an augmented reality application (URL-1, 2020). 

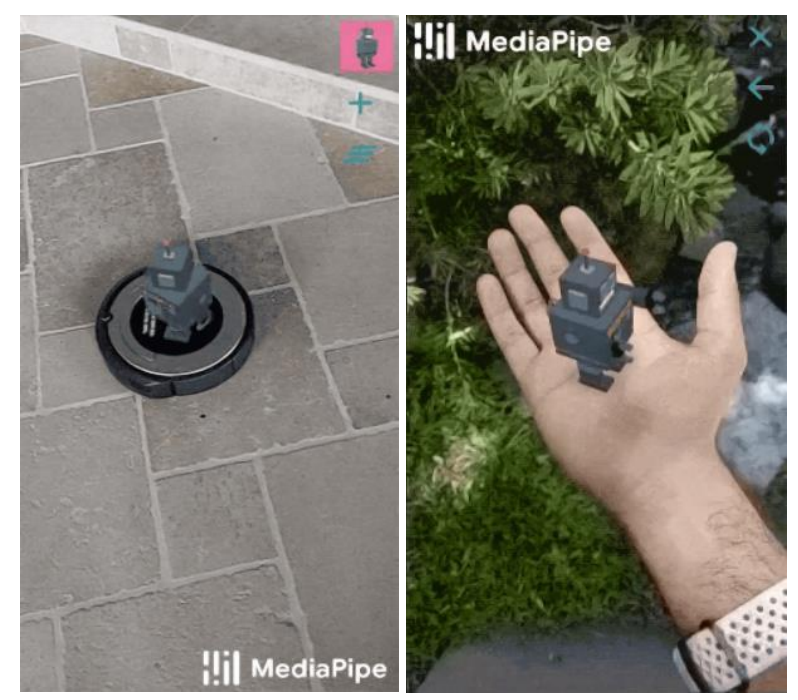

Figure 3: The object is placed on the image and it follows moving objects to change its position to create a hybrid environment (URL-2, 2020)

\subsection{Representation Models and Techniques of Forms in Digital Environment}

In architecture, besides producing solutions, it is also important to choose one of them that meets the desired conditions. Various software using representation, visual evaluation and geometric modeling techniques are used for this purpose. These techniques, which provide the geometric definition of the architectural form, have followed a progress from the technique of expression with lines to surface, mass and object models based on database. Mitchell (1990) describes these representations both as data structures and architect's interpretation of geometrical shapes and volumes. They can generally be examined in three groups (Figure 4).

- Wireframe model: In this technique, design product is represented with only its edges.

- Surface model: 3D objects defined with wireframe technique are filled as surfaces.

- Solid / Void model: Objects are visualized with basic geometric volumes.
Pixel, voxel, vector and nurbs techniques are used while defining geometric models:

- Pixels: A pixel defines a pair of coordinates in a two-dimensional coordinate system and it is written by $(\mathrm{x}, \mathrm{y}$, PR) notation.

- Voxels: Voxel is the expression of the pixel definition according to threedimensional coordinate system and it is written as (x, y, z, PR). In these techniques, PR refers to unit properties.

- Links: Combining neighboring coordinate points creates links.

- Vector: This definition technique is based on the generalization of links, in other words, the combination of any pair of coordinates that are not adjacent to each other. Two-dimensional definition is written as $(x, y, x 1, y 1)$ notation, threedimensional definition is written as $(\mathrm{x}, \mathrm{y}, \mathrm{z}$, $\mathrm{x} 1, \mathrm{y} 1, \mathrm{z} 1)$ notation.

- Nurbs: Non-Uniform Rational B-Splines is shortened as nurbs. It is one of the mathematical expression methods of 3 dimensional curves. It is used to express geometric shapes such as cones, spheres, or cylinders. These forms have known mathematical equations that express them.

Geometrical models of complex shapes can be constructed on the computer with form algebra operations or boolean operations (combination, intersection, subtraction) applied to the shapes defined by these techniques. Also, "move, replace, change scale, copy, mirror, rotate, cut, stretch, subtract" operations are used to produce forms in the design process. In this article, wireframe modeling and vectors are used for 3D sketching, and solid modeling and voxels are used for mass modeling. 

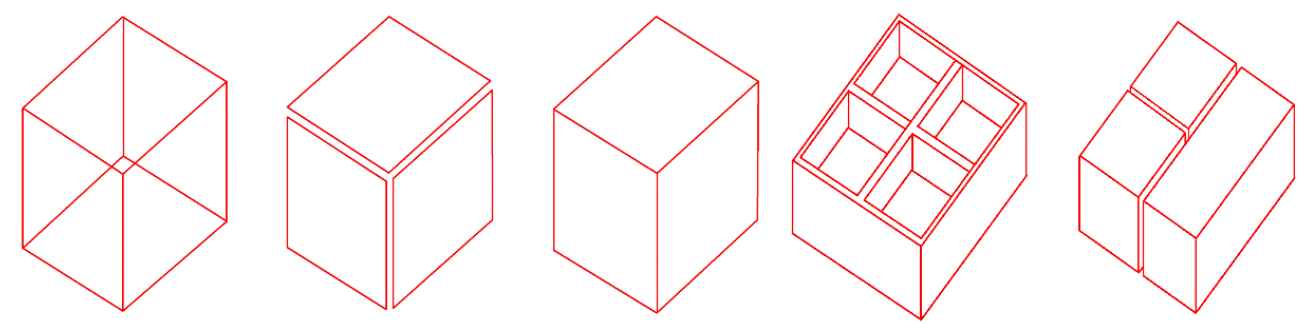

Figure 4. Model types (Mitchell, 1990).

\section{Mobile Design Environment and Its Interface}

The early working phase in architectural design is a continuous process in which ideas are produced, interpreted, changed and fundamental design decisions are made. Making such a task more efficient means affecting the quality and time variables related to the architectural activity. Therefore, in the scope of this study, a mobile design application has been developed to increase the efficiency of the design process. By using this digital environment, early design activities can be supported with easily accessible devices such as mobile phones and tablets that people can carry with them at any time.

The goal is to develop an application similar to physical model environment productivity in order to test mass alternatives with surrounding structures and topography in the project area in the first stage of architectural design.

Unity 3D game engine software is used to create the model. Unity 3D works with object-oriented C\# programming language support. Codes written in this language are assigned to objects in the scene, they can be edited with any code editing software. Many improvements can be added to the software as extension libraries. As of now, it is possible to publish and run the developed applications on 27 different platforms. Although it has a game-oriented style, its support for mobile devices and augmented reality makes it a suitable development environment for this research (Url-3). Google ArCore plugin was used for AR infrastructure (Url-4). In this way, a markerless AR system can be set up. In free hand design activities and quick studies, it is important for the tool to be easily accessible at all times.

\subsection{Workflow of the Application}

The activities carried out in the application are divided into two main groups as "Object Modeling" and "Sketch actions". Accordingly, solid object creating actions mimic real-world modeling activities. Sketch actions get inspiration from the idea of drawing lines with a pencil on a 3-dimensional plane. Solid model and voxel techniques define units of a volume and vectorial lines are used in the sketch method.

Each user chooses their own starting scenario for form generation. For their project, users can work with the existing environment. Scale relationship can be better established when a real object is taken as reference. For example, a site model with surrounding buildings is created first. Then the form creation study in AR environment can be carried out with the nearby physical elements. This way user defines a scale for the object worked on. Secondly, design can be studied in a completely empty virtual space. This helps with the quickest form production approach because object size is not referenced to any object. Also, it can be adjusted at the end of the study. After this part, the mobile device is held to a surface to bring the virtual plane and the physical environment together and one of the 3 modeling techniques is chosen. In Figure 5 , the operations of the program are explained. There are 3 main methods that can be changed during the design process. 


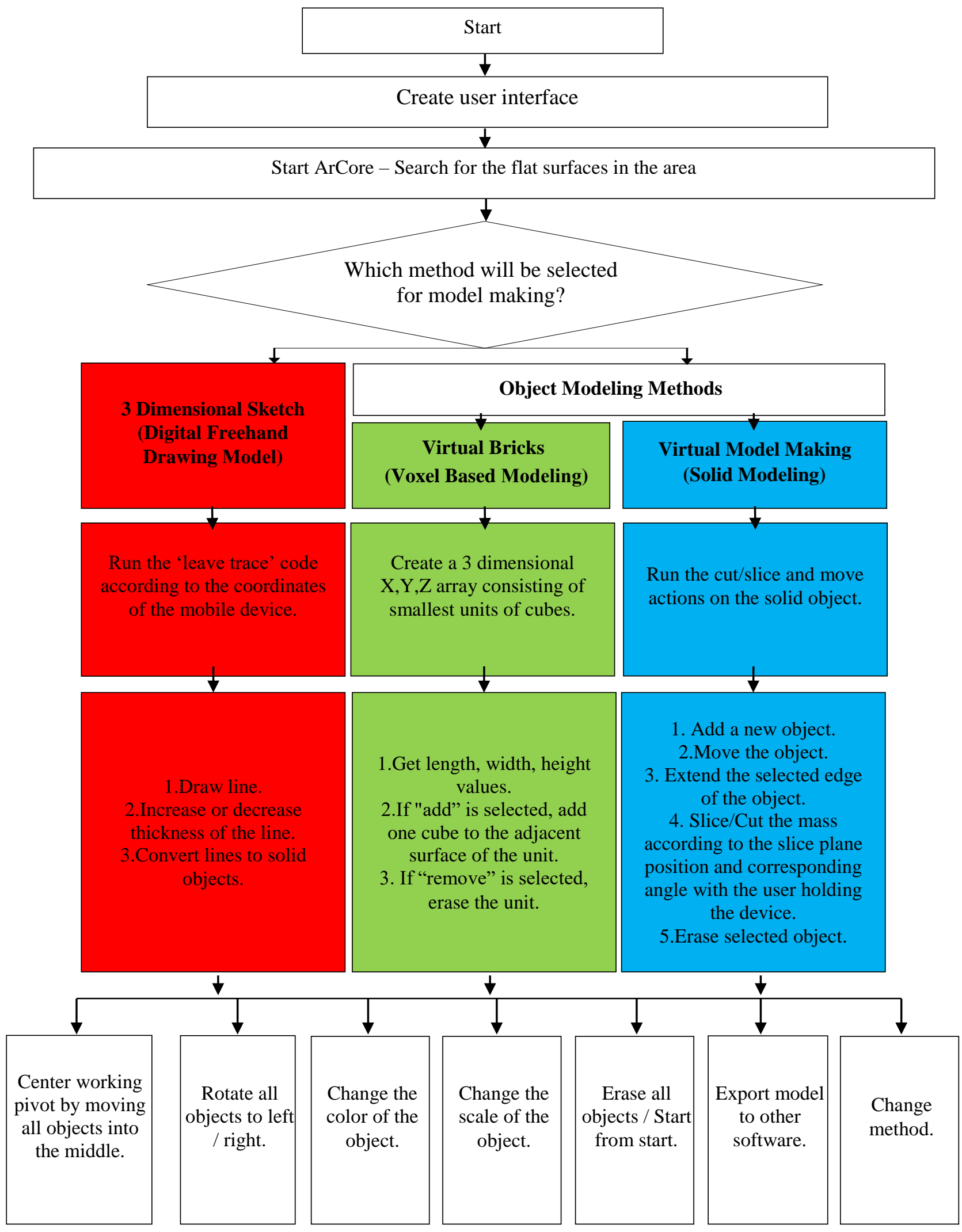

Figure 5. Main operations for the model. 


\subsection{Application Interface}

In the proposed mobile media interface, the upper portion of the screen is used for augmented reality video streaming. At the lower part there are buttons for program commands. Gray colored left side buttons are available in all three interfaces. Red, green, blue colored buttons represent the three main model making methods. Method switch button is at lower right for changing the modeling technique. In Figure 6, there are three main screens.
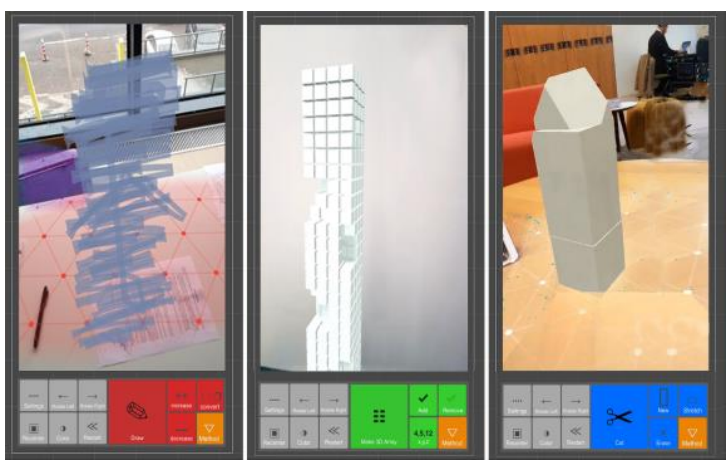

Figure 6. Mobile environment interface: From left to right; $3 D$ sketch, Virtual Bricks, Virtual Model Making screens and an application example.

General command buttons are seen in Figure 7.

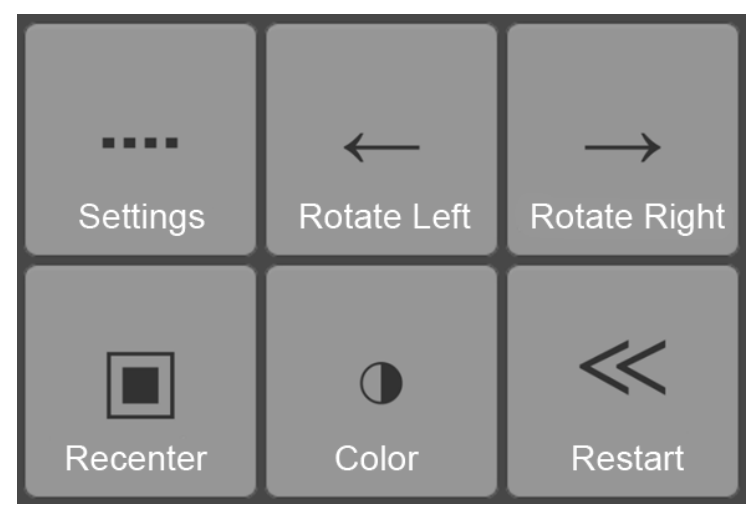

Figure 7: Assisting buttons for all methods.

The functions of the keys are explained below:

1. Settings: File export, scale and other secondary commands appear when this is selected.
2. Rotate Left: Rotates all objects counterclockwise. (User can also walk around the object.)

3. Rotate Right: Rotates all objects clockwise.

4. Center: This is used when recentering is necessary.

5. Color Change: With every new object there is a new color assigned to the new unit.

6. Restart: Erases all objects in the scene.

Figure 8: Line scale: Normal positioning means 1:1 model, it can be changed by sliding left or right.

3-dimensional sketching (digital freehand drawing) button layout is shown in Figure 9.

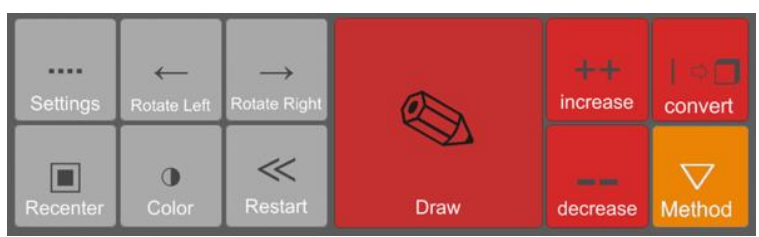

Figure 9: Button layout for sketching interface.

1- Draw button: As user holds the button and move the mobile device in the air, a 3dimensional line is drawn. When user releases the button and press it again, a new line is drawn. It is an action emulating the pen touching the paper and leaving a trace.

2- Increase thickness button: Next line will be drawn thicker.

3- Decrease thickness button: Next line will be drawn thinner.

4- Convert the line button: A circular section profile is drawn along the line from start to the end.

Figure 10 shows the graphic depicting the location of the virtual pen in the 3D sketch and a drawing. The user draws freehand lines in the air by moving the device freely. 


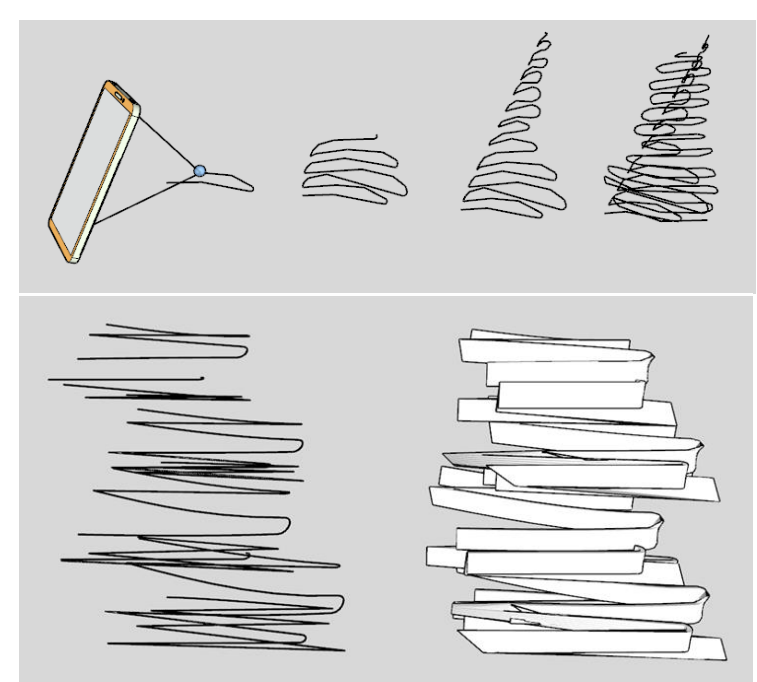

Figure 10: The drawing shows the positioning for the virtual pen and two examples of free-hand $3 D$ sketches.

Green colored buttons for voxel-based production called virtual bricks are shown in Figure 11.

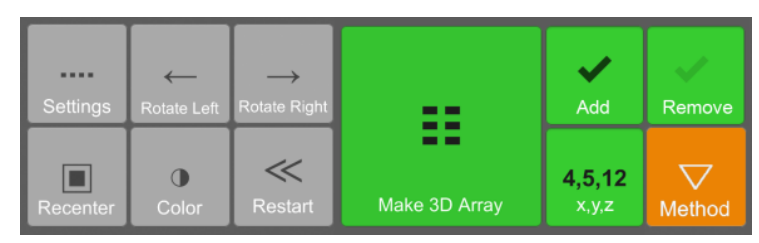

Figure 11: Button layout for voxel-based production.

1. Create an array: It produces a 3-dimensional array based on the measurements entered by the user.

2. Size: User enters new dimensions for a new array.

3. Add: With the adding mode selected, each time users touches a cube, a volume is created nearby on the adjacent surface.

4. Remove: When remove mode is chosen, the target unit is erased with touch input.

In Figure 12, the graphics about addition and subtraction are explained. An application of this modeling is shown in Figure 13. It is possible to create a volume in digital space by creating a unit on the $\mathrm{X}, \mathrm{Y}$ then $\mathrm{Z}$ axis and applying add and subtraction actions. In the addition mode, when the surface of the unit is touched, a new object is created on the neighboring surface.

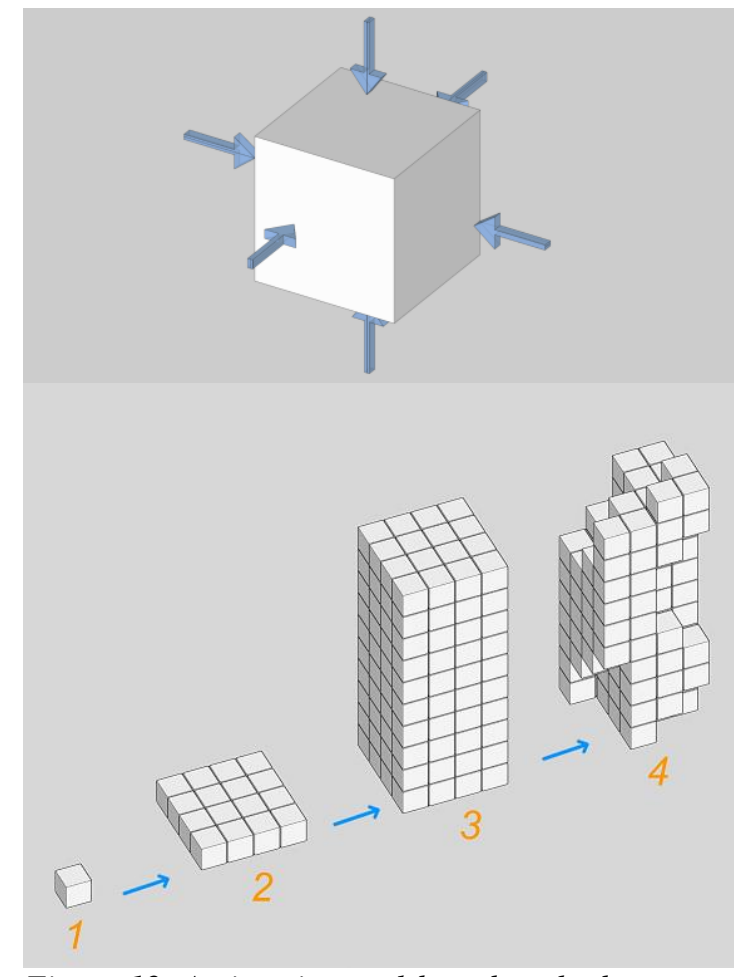

Figure 12: Actions in voxel-based method.

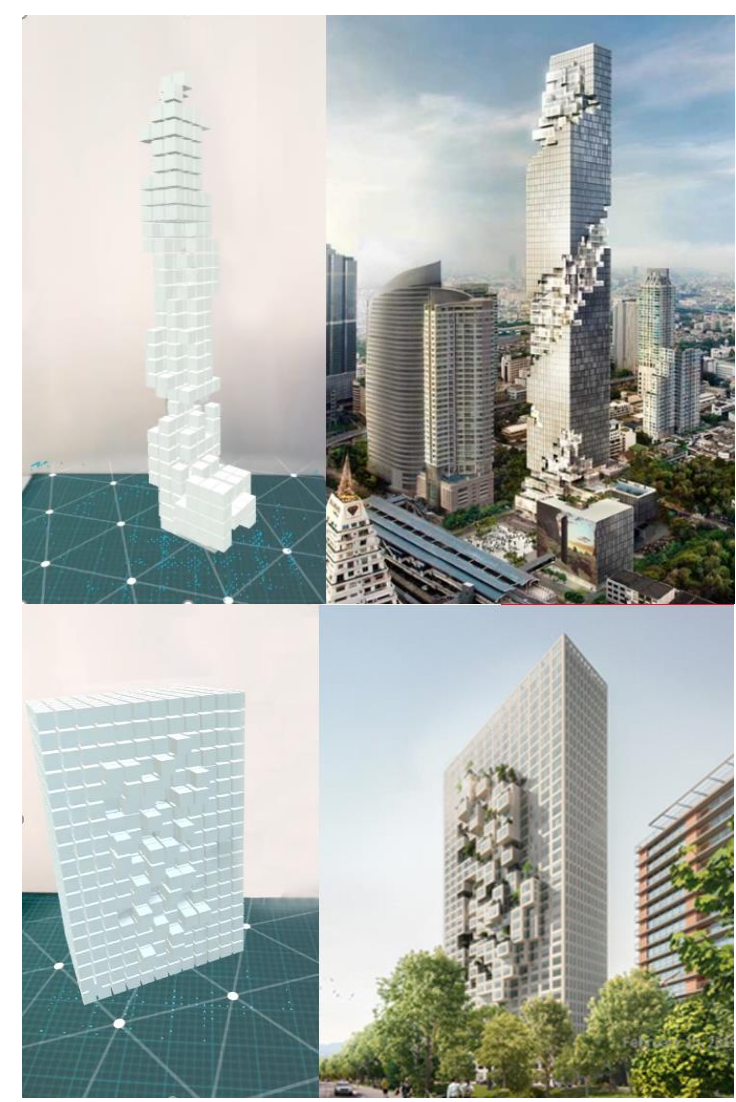

Figure 13: Example studies for two different masses using virtual bricks method (Url-5, Url-6). 
In the virtual modeling (solid modeling) method, the buttons are highlighted in blue (Figure 14). In this method, a starting object is placed and manipulated by cutting it and pulling its edges.

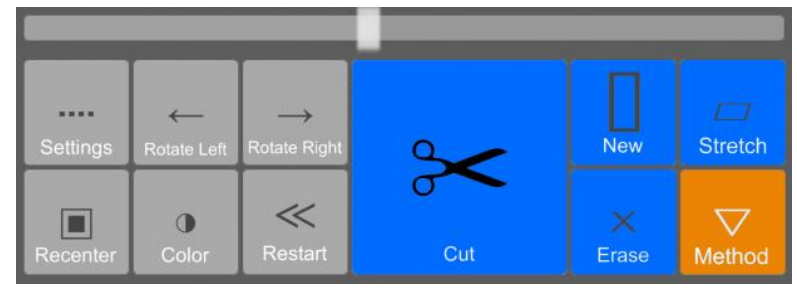

Figure 14: Button layout for virtual modeling.

1. Slice / Cut: It cuts the object with the cutting plane that intersected with it.

2. New Object: Creates a new box primitive to the virtual environment.

3. Pull/Push: User moves the object's edges to deform it.

4. Remove: Erases object.

Figure 15 shows the relationship of the cutting plane with the object and the final view after several cutting operations.

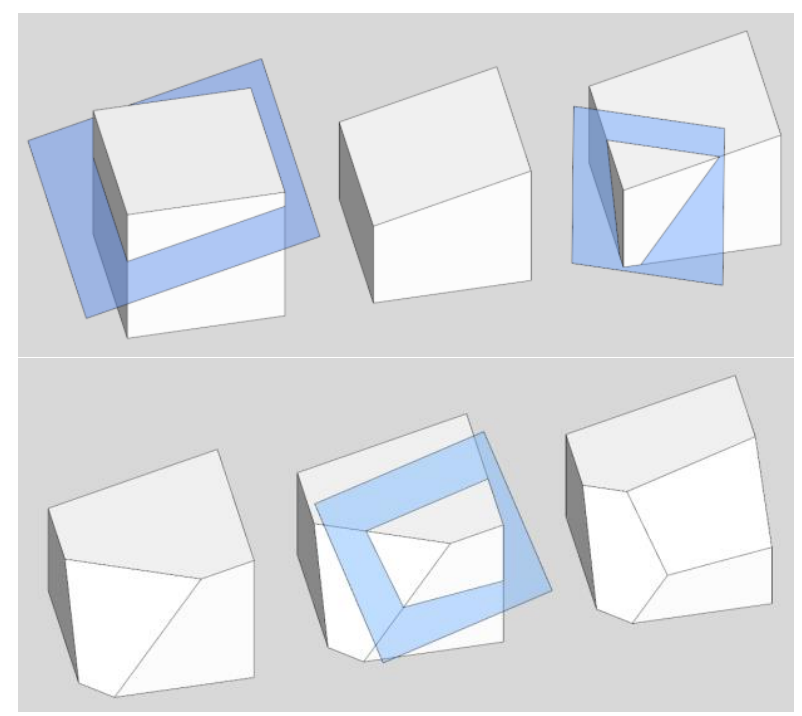

Figure 15: Image explaining relation between cutting plane and the mass.
To test the mobile application, the subject of high-rise building is chosen. Since the form design problem is more prominent in high-rise buildings, this building typology will provide a suitable basis for evaluating the proposed digital workspace (Figure 16).
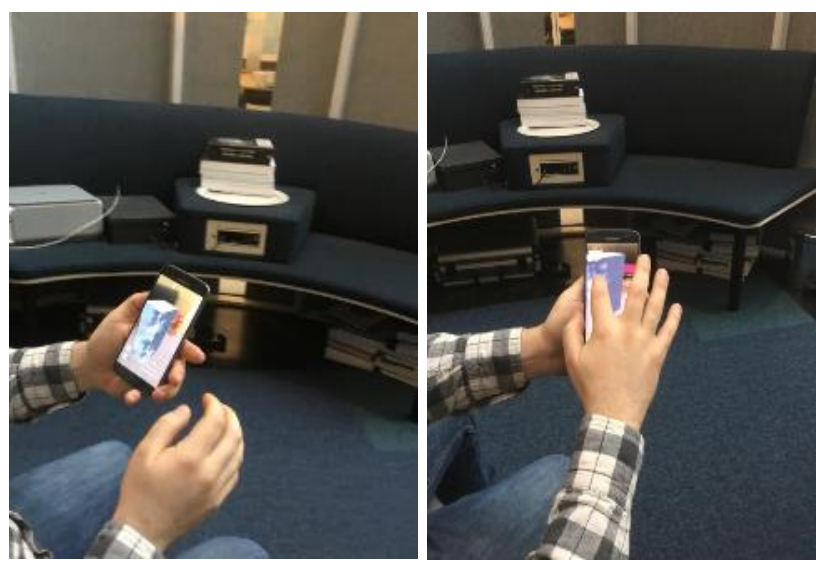

Figure 16: An architect using the application.

In Figure 17, comparisons of two studies are displayed. While testing with the users, building examples are shown to each user. The buildings list consists of 30 projects designed by architects in various parts of the world. They are selected by their different characteristics in terms of form and they have different façade properties. These initial sketches or models are shown to the users and they are asked to make similar models by using the mobile application.

At the end of the application, solid models developed in mobile environment can be sent to rapid prototyping tools and $3 \mathrm{D}$ prints can be produced (Figure 18). OBJ formatted output files can be transferred to other modeling software, giving the opportunity to continue and develop for designing in detail. 

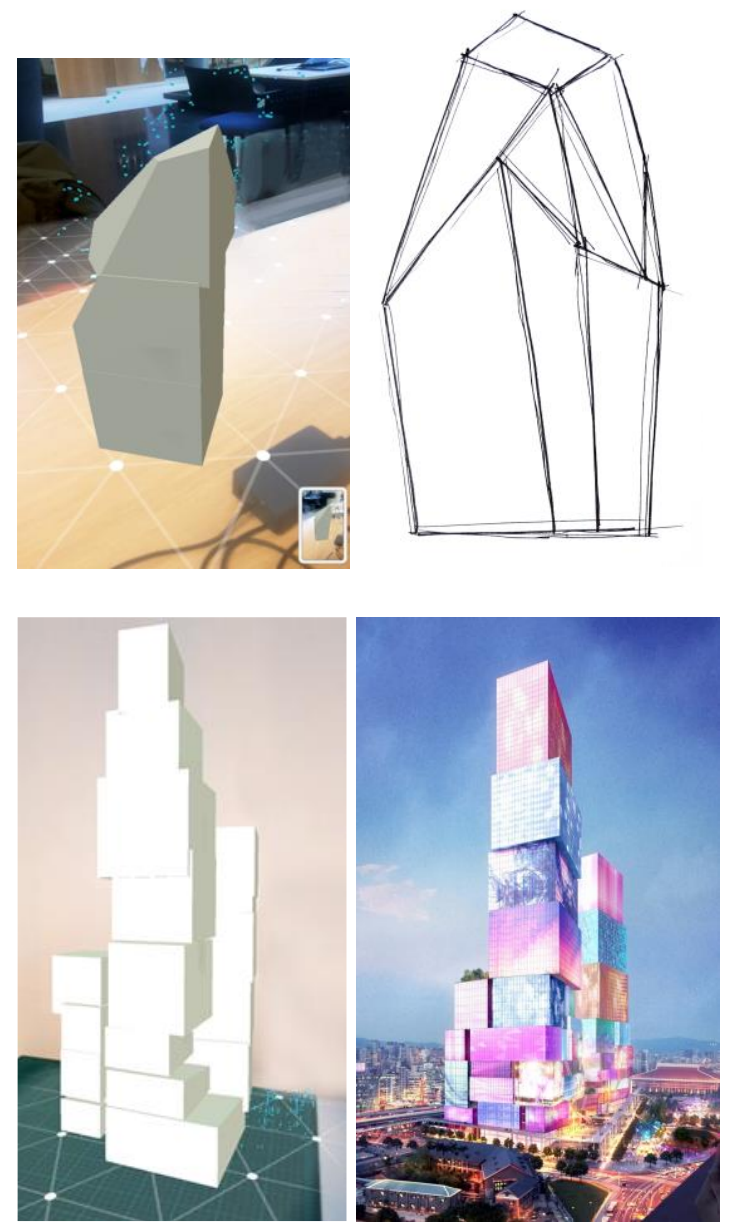

Figure 17: Objects are modeled using cutting and scaling techniques (Url-7).

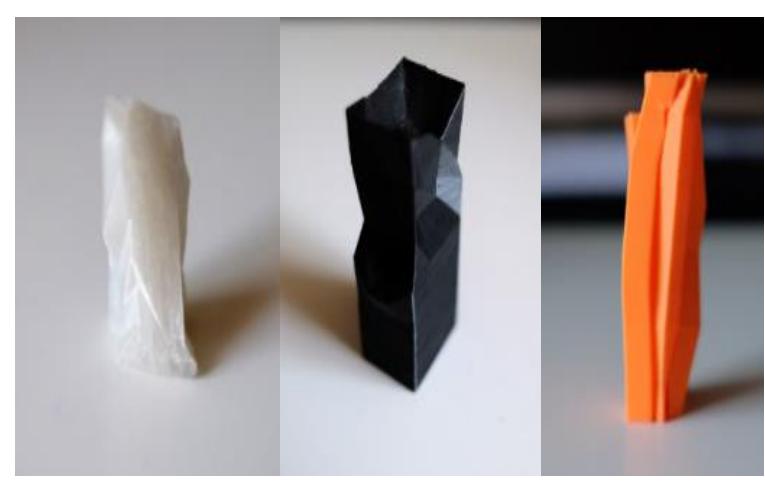

Figure 18: Prototyping examples for the forms developed in the mobile application.

\subsection{Evaluation of the Application}

To evaluate the mobile AR application, 10 architects with professional experience were asked to select a project from the example highrise building list and model a similar form. At the end of the study, feedback about the process were measured with the help of a 9-question survey. The answers have 5 ratings in Likert standard with the options; "Absolutely disagree, Disagree, Undecided, Agree and Strongly agree" as shown in Table 1.

Table 1. The questionnaire for the evaluation of the mobile application.

\begin{tabular}{|c|c|}
\hline Question 1 & $\begin{array}{l}\text { It allowed me to quickly } \\
\text { visualize my thoughts on } \\
\text { design. }\end{array}$ \\
\hline Question 2 & $\begin{array}{l}\text { I developed new ideas during } \\
\text { the study. }\end{array}$ \\
\hline Ques & $\begin{array}{l}\text { I was able to visualize my } \\
\text { thoughts on design faster than } \\
\text { the drawing / } 3 \mathrm{D} \text { program I } \\
\text { used. }\end{array}$ \\
\hline Ques & $\begin{array}{l}\text { I can transfer the model to my } \\
\text { drawing environment and } \\
\text { continue to develop it. }\end{array}$ \\
\hline Que & $\begin{array}{l}\text { Solid modeling method is } \\
\text { useful. }\end{array}$ \\
\hline Quest & Sketching in $3 \mathrm{D}$ is useful. \\
\hline Question 7 & $\begin{array}{l}\text { It was easy for me to learn how } \\
\text { to use the tool. }\end{array}$ \\
\hline Que: & $\begin{array}{l}\text { I think the application is a } \\
\text { suitable environment for the } \\
\text { form design problem. }\end{array}$ \\
\hline Question 9 & $\begin{array}{l}\text { I can use this tool to start a new } \\
\text { design. }\end{array}$ \\
\hline
\end{tabular}

The design processes and final products of the users participating in the experiment were recorded with the screen recorder on the device, and then the scores in the questionnaire were collected. As we can see from the results in Table 2, the expectation of being fast and 
effective in the proposed application criteria are met. In addition, potential in generating new ideas were there, and the method of drawing with a 3D pencil, which architects were familiar with before, got the highest score. Also, these results show that users rely on their preferred 3D modeling software for fast modeling. Although 3 completely new methods were presented to users, it is clear that there was no difficulty in terms of adaptation to these approaches.

Table 2. Questionnaire results.

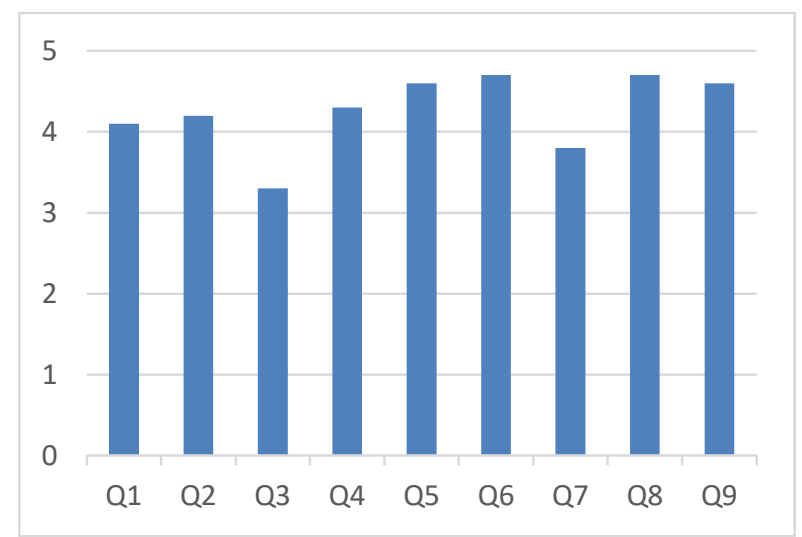

\section{Conclusion}

Within the scope of this study, a digital mobile tool has been developed that will provide rapid production of alternative form generation in the early design. To support productivity in the design process, the software has been shaped with the following five goals:

- Sketch-like thinking: The model being worked on is not a finished product. The vague nature in the sketch study can be reflected in the digital working environment and the search for form can be supported.

- Fast creation: It allows the model generation to be quick and the remaining time can be used with the design again.

- Natural interaction: It allows to utilize the hand and brain coordination that the architect is used to work by, in a virtual environment.
- Real time feedback: Operations in virtual environment are done in real time. The actions and the results seen on the screen are experienced at the same time.

- Transformation operations: Simple transformations can be applied on the object in the virtual environment.

This study aims to contribute to the creation of ideas in the early architectural design phase. It presents an augmented reality supported approach for initial design activity. It is tested by 10 architects with professional experience and the research goals are consistent with the survey results. This tool can be transformed into a design environment that is not only limited to tall buildings, but also it can help with design problems of all types and scales.

Created virtual objects can be exported to another file. Later, it can be used with other design tools in the computer environment. In addition, the collaborative working feature can be added to the digital production environment. Multiple users can participate in the study synchronously. This mobile environment, which can also offer the opportunity to work remotely, is expected to increase communication and add more value to the activity.

\section{References:}

Ackerman, J. S., \& Slosburg-Ackerman, J. (2002). Origins, imitation, conventions: representation in the visual arts. MIT Press.

Akin, O. (1978). How Do Architects Design? In Artificial Intelligence and Pattern Recognition in Computer Aided Design, ed. J.-C. Latombe. IFIP: North-Holland Publishing Company.

Arashpour, M., \& Aranda-Mena, G. (2017). Curriculum renewal in architecture, engineering, and construction education: Visualizing building information modeling via 
augmented reality. In 9th International Structural Engineering and Construction Conference: Resilient Structures and Sustainable Construction, ISEC 2017. ISEC Press.

Azuma, R., Baillot, Y., Behringer, R., Feiner, S., Julier, S., \& MacIntyre, B. (2001). Recent advances in augmented reality. IEEE computer graphics and applications, 21(6), 34-47.

Bayazit, N. (2004). Investigating design: A review of forty years of design research. Design issues, 20(1), 16-29.

Birt, J., Manyuru, P., \& Nelson, J. (2017). Using virtual and augmented reality to study architectural lighting. Me, Us, IT, 17-21.

Füssler,U 2008, “Design by Tool Design', in Proceedings of Advanced in Architectural Geometry (AAG'08), Vienna, Austria.

Goldschmidt, G. (1991). The dialectics of sketching. Creativity research journal, 4(2), 123-143.

Kerr, J., \& Lawson, G. (2020). Augmented reality in design education: landscape architecture studies as AR experience. International Journal of Art \& Design Education, 39(1), 6-21.

Koutamanis, A. (2003). A Biased History of CAAD: The bibliographic version. In Proceedings of eCAADe (Vol. 23).

Milgram, P., Takemura, H., Utsumi, A., \& Kishino, F. (1995, December). Augmented reality: A class of displays on the realityvirtuality continuum. In Telemanipulator and telepresence technologies (Vol. 2351, pp. 282292). International Society for Optics and Photonics.

Mitchell, W. J. (1990). The logic of architecture: Design, computation, and cognition. MIT Press.
Suwa, M and Tversky, B What do architects and students perceive in their design sketches?: A protocol analysis, Design Studies Vol 18, No:4 (1997), pp 385-403.

Smith, K. S. (2012). Architects Sketches. Routledge, 2-11.

Sutherland, I. E. (1964). Sketchpad a manmachine graphical communication system. Simulation, 2(5), $R-3$.

Thomas, P. C., \& David, W. M. (1992). Augmented reality: An application of heads-up display technology to manual manufacturing processes. In Hawaii international conference on system sciences (pp. 659-669).

URL-1, Pivot App. Retrieved 06.10.2020, from http://www.pivottheworld.com,

URL-2, Google Developers Blog. Retrieved 06.10.2020, from http://developers.googleblog.com /2020/08/instant-motion-tracking-withmediapipe.html

URL-3, Unity. Retrieved 06.10.2020, from http://www.unity3d.com

URL-4, Google ARCore. Retrieved 06.10.2020, from http://developers.google.com /ar/discover

URL-5, MahaNakhon - Büro Ole Scheeren. Retrieved 15.11.2020, from https://buroos.com/projects/mahanakhon

URL-6, DownTown One Tirana - MVRDV. Retrieved 15.11.2020, from https://www.mvrdv.nl/ projects /388/downtown-one-tirana

URL-7, Taipei Twin Towers - MVRDV. Retrieved 15.11.2020, from https://www.mvrdv.nl/ projects/371/taipeitwin-towers 